\title{
Testing the Effects of a Thermal Power Plant Combustion by-Product Stabilizer on Water Impermeability
}

\author{
Martin Bosák ${ }^{1 *}$, Michal Tkáčํ, Marián Holub², Alexander Tarča ${ }^{1}$, \\ Petra Szaryszová ${ }^{1}$, Lenka Štofová ${ }^{1}$
}

${ }^{1}$ Faculty of Business Economics in Košice, University of Economics in Bratislava, Košice, Slovak Republic

${ }^{2}$ Faculty of Civil Engineering, Technical University of Košice, Košice, Slovak Republic

Received: 31 October 2018

Accepted: 6 March 2019

\begin{abstract}
Fossil fuels as black coal, crude oil and natural gas are at present still the main sources of energy production. Thermal energy is the second most important source in Slovakia (after electricity), representing almost $13.6 \%$ of total energy production. One Slovak power plant, Vojany Power Plant (EVO), sees an undesirable by-product of coal combustion as ash, which is deposited on the tailing ponds and a stabilizer deposited on a landfill. The aim of our paper is to formulate conclusions from laboratory testing and testing field results of combinations of stabilizer as a by-product, waste from combustion, and from EVO desulphurization technology in combustion processes. The reinforcement of the stabilizers with cement and lime was realised for forming the sealing respectively water-permeable layer. The reason for testing was the use of stabilizer for tailing pond reclamation as a component of the underlying impermeable part. This can attain an environmental as well as economical solution for the use of stabilizer and waste from thermal power plants.
\end{abstract}

Keywords: stabilizer, testing, laboratory experiments, water impermeability, Vojany Thermal Power Plant

\section{Introduction}

Although alternative sources of energy have come to the fore in the last four decades, the use of coal as a source of energy cannot be ruled out. [1] The resulting by-products from combustion of coal in the form of fly ash and bottom ash, as well as their mixtures with the residues from the flue gas desulfurization process, cause significant economic and environmental problems. A relatively small percentage of the material finds application in construction as an additive to cement and other construction products in mining, machinery and agriculture, but the vast majority of the material that is produced every year is deposited in landfills [2-4]. The advantages and disadvantages of the potential use of coal ash in soil improvement, construction, and ceramics are 
also considered by authors Yao et al. (2015). [5] Jayanthi and Singh (2016) define these applications in industry as "sustainable materials" in stabilizing and modifying the soil [6].

The use of ash in areas such as new materials, waste management, metal recovery and agriculture is being analysed by the authors to explore new areas that enhance the positive reuse of ash, thereby helping to reduce the environmental and economic impacts of disposal. [4].

Phanikumar and Sharma (2007) applied ash on sandy soil to improve water retention capacity. This improvement in water retention capacity is beneficial to plant growth - especially in the case rainforest farming. Changing soil composition with fly ash up to $40 \%$ increased soil porosity from $43 \%$ to $53 \%$ and water retention capacity changed from $39 \%$ to $55 \%$ [7].

However, the benefits of the development of the etching process are still under discussion. It has been found that this new type of additive can be used to stabilize the soil for underlying purposes. [8]

It is the result of their physical and chemical properties that meet the technical requirements defined in the sectoral standards as well as the environmental requirements relating in particular to water and soil protection. As a raw material for the production of cement, concrete, ceramic materials, fertilizers or soil additives or storage materials used in mining can use ash from biomass as coal ash, which is the subject of research studies in many countries of the world [9-14], in Asia, China [15], India [16, 17] and also in Europe, in Poland [18-21], Italy [22] and in Slovakia [23].

\section{Materials and Methods}

The percentage of use of coal ash and stabilizer in various construction activities is still limited in Slovakia compared to other countries. As a progressive use of stabilizer in Slovakia, its use is being tested using a new technology for reclamation of the tailing pond, where the stabilizer would be used when composing the waterpermeable layer. The composition and properties of the fresh stabilizer (stabilizer directly from the combustion processes) and the old stabilizer (stabilizer stored in the landfill) are different, so samples of both species were tested. The fresh stabilizer deposited at the stabilizer landfill changes its properties over time and hardens due to access to rainwater. Its landfills at the EVO and Nováky Power Station provide huge supplies. Use of the fresh stabilizer will not only help the environment, but can also bring an economic effect, as it is the use of waste. The object of the research was the stabilizer obtained from the EVO's landfill. Thermal power plant EVO is situated in Eastern Slovakia in Michalovce District. The advantageous location in the proximity of the Slovak-Ukrainian border, the utmost shortening of the semi-anthracite coal wide-gauge track from the Donbas-Kusbeck mining area and the possibility of cooling water off-take from the Laborec River were the most important considerations leading to the decision to build this plant. By supplying base power the plant ensures reliability of the transmission network in eastern Slovakia and also provides ancillary services for the power system necessary to sustain the stability of the system qualitative indicators.

A laser granulometry method using the Mastersizer 2000 laser granulometer (Malvern, UK) was used to determine the shares of fine-grained particles in samples of the stabilizers. Analysed was the overflow of particles via a $0.063 \mathrm{~mm}$ sieve. Three dry-count measurements were performed on each sample of the stabilizer. The average values are presented in the results of the research.

Authors of the research paper tested the permeability of the stabilizer in two ways:

A) The permeability of the combination of old and fresh stabilizer.

B) The permeability of the stabilizer mixture with cement and lime.

A) To test the permeability of the stabilizer the mixture formed by the combination of the old and the fresh stabilizer was created in 8 different test bodies (TB) designated TB1 to TB8. Testing bodies were designed with a dual combination of stabilizers:

- Mixing the old and fresh stabilizer in a certain proportion into the homogeneous mixture TB1, TB2, TB3, TB4, TB5 and TB8.

- Creation of layers of old and fresh stabilizer with vertical heterogeneity TB6 and TB7.

The more detailed compositions of each sample are:

- TB1 $-100 \%$ fresh stabilizer.

- TB2 - stabilizer mixed in a ratio 50:50\% (fresh:old).

- TB3 - stabilizer mixed in a ratio 90:10\% (fresh:old).

- TB4 - stabilizer mixed in a ratio 70:30\% (fresh:old).

- TB5 - stabilizer mixed in a ratio 30:70\% (fresh:old).

- TB6 - stabilizer deposited in two $15 \mathrm{~cm}$ layers (on the top the fresh stabilizer and at the bottom the old stabilizer).

- TB7 - stabilizer deposited in three $10 \mathrm{~cm}$ layers (on the top the fresh stabilizer, in the middle the old stabilizer and at the bottom the fresh stabilizer).

- TB8 $-100 \%$ old stabilizer.

The stabilizer was in the tubes, respectively in the columns filled gradually in layers up to $30 \mathrm{~cm}$ and each layer being compacted. This procedure was chosen to ensure the uniformity of the preparation of test samples.

Testing of hydraulic conductivity and calculation of the filtration coefficient was performed by the variable height level method. This method is simple to implement and is sufficiently noticeable for medium- and lowpermeability substrates. The observed parameters in this study were the initial height of the level, the final height above the surface of the sample, and the time at which this change of the level occurred. The mathematical expression of the filtration coefficient is given in the following equation: 


$$
k=\frac{a \times L}{A x t} \ln \frac{h_{0}}{h_{t}}
$$

...where:

$\mathrm{k}$ - Coefficient of permeability [m/s]

$\mathrm{a}-$ The cross sectional area of the tube $\left[\mathrm{m}^{2}\right]$

L - Sample length [m]

A - Cross-sectional area of the sample $\left[\mathrm{m}^{2}\right]$

$\mathrm{t}$ - The time at which a given drop in level occurred

$\mathrm{h}_{0}$ - Height of the level at the start of the test

$h_{t}$ - Height of the level at the end of the test

Prior to testing, the samples had to be saturated to avoid distortion of the results due to the absorption of tap water. The prepared samples were saturated with a $30 \mathrm{~cm}$ column of water for 24 hours.

B) The materials containing calcium hydroxide were used to re-stabilize the stabilizer, providing the course of the puzzolanic reaction. For this use, white limes CL 90 Q, CL 80 Q or dolomite lime DL 90-30 are suitable in a fixed percentage by weight of the stabilizer, which must meet the requirements of STN EN 459-1.

To improve the properties of the stabilizer, cement meeting the requirements of STN EN 197-1 may also be used. For use are also suitable cements CEM II strength class with normal initial strength (N) and CEM III strength class 32.5 with low (L) initial strength or with a normal initial strength $(\mathrm{N})$ in a determined percentage.

The prepared 4 experimental fields were placed on the pond area according to the planned scheme (Fig. 1). During their construction we used:

- Lime - SpeziKalk, lime hydrate CL90-S.

- Cement II - Portland cement B-M, 32.5 N.

- Cement II - Portland cement B-S, 42.5 N.

These materials were also used during laboratory testing and sample preparation under laboratory conditions (ex situ).

The composition of 4 experimental fields was as follows:

1. One field with the old stabilizer with lime addition $0 \%, 2 \%, 4 \%$ and $10 \%$ (reference field - pure stabilizer).

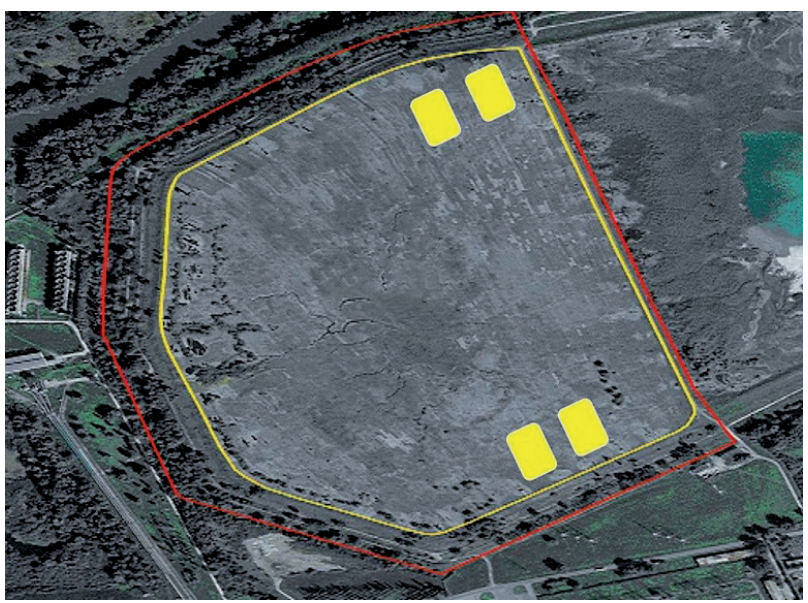

Fig. 1. Placement of experimental fields on the tailing pond.

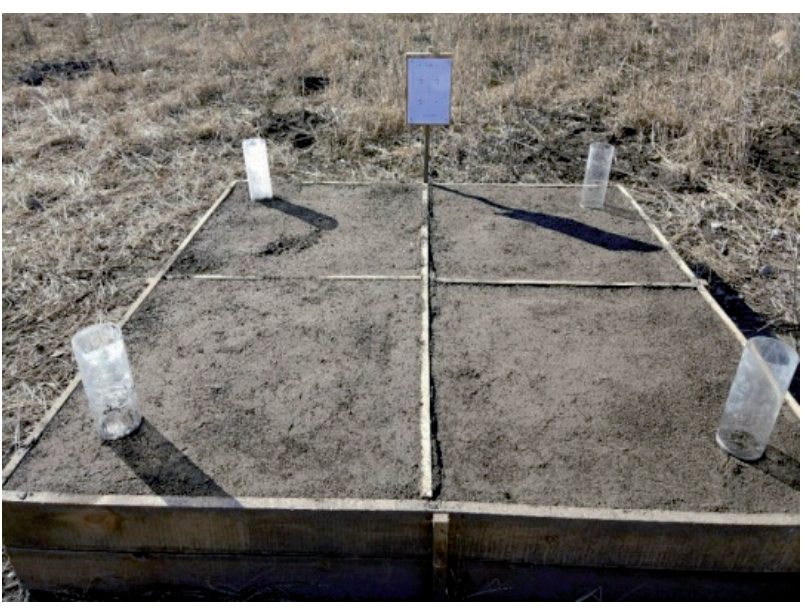

Fig. 2. Placement of the test columns on the field.

2. One field with old stabilizer with cement addition C1 CEM III strength class $32.5 \mathrm{~N} 0 \%, 2 \%, 5 \%$ and $10 \%$.

3. One field with old stabilizer with cement addition $\mathrm{C} 2$ CEM II strength class $42.5 \mathrm{~N} 0 \%, 2 \%, 5 \%$ and $10 \%$.

4. One field with the fresh stabilizer with lime addition, respectively two types of cement containing $2 \%$.

The stabilizer from the landfill of stabilizer was modified by crushing and at the same time mixed with lime, respectively cement. Fresh stabilizer was mixed in the same way.

Compaction of the stabilizer on the experimental fields was carried out in about $100 \mathrm{~mm}$ of coarse layers by rolling. The compaction took place until a final height of testing field $300 \mathrm{~mm}$ was reached, while the edges of testing fields with $1000 \times 1000 \mathrm{~mm}$ (net area) were bounded by a wooden structure for better compaction.

The testing methodology used in this research was in situ and ex situ:

In situ - After the testing/experimental fields were made, infiltration tests were performed in situ. Although the original methodology considered drilling of the test bodies from the area of the fields and their ex situ testing, due to the hardness/homogeneity of the stabilizer, infiltration tests were finally carried out right in the place.

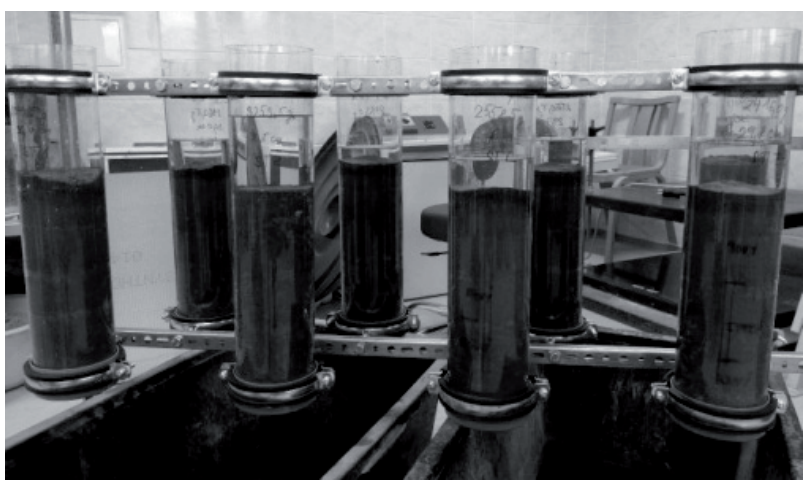

Fig. 3. View of filled columns during testing. 


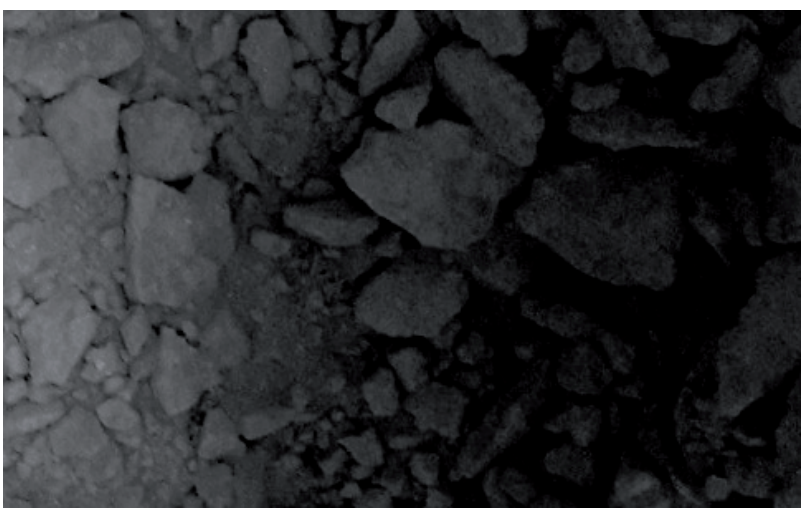

Fig. 4. View of old stabilized sample taken before crushing.

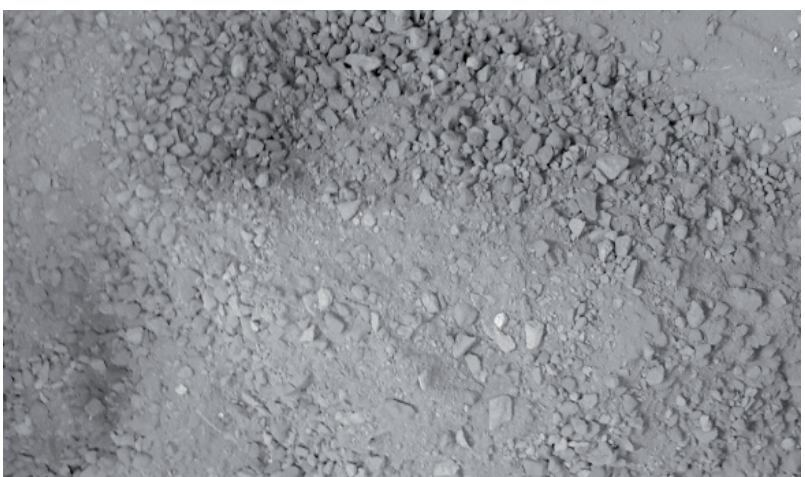

Fig. 5. Sample of old stabilizer after crushing.

The variable height level measurement was performed for hydraulic conductivity testing and calculation of the filtration coefficient. Test columns were dropped to a depth of 20-22 cm (Fig. 2) in each testing field.

The initial saturation was performed for 30 minutes before the measurement itself. Subsequently, the level of $h_{0}$ was subtracted and after 30 minutes the $h_{t}$ level. Realization of infiltration tests took place 90 and
120 days after realization of testing fields.

Ex situ - Measurements to determine the filtration coefficient were performed simultaneously under laboratory conditions to compare the results obtained in situ. The procedure for filling the laboratory columns was the same as on the pond (Fig. 3).

To test the permeability of the stabilizer or of the mixture formed by the combination of stabilizer and admixture, 14 combinations were generated that reflected the composition of the testing fields directly on the pond. The procedure was chosen to compare the laboratory and field permeability values achieved.

\section{Results and Discussion}

For the purpose of testing the stabilizer, the grain composition of the old and fresh stabilizer was found as an input parameter. The old stabilizer is naturally encased in weather conditions, i.e., a chemical reaction that occurred after its initial contact with water and also compaction during landfilling. The old stabilizer (Fig. 4) was therefore firstly adjusted by crushing for the purpose of testing its hydraulic conductivity (Fig. 5). To determine the granulometric composition of the old and fresh stabilizer, sieve analysis was performed using sieves with the following hole sizes: $16 \mathrm{~mm} ; 8 \mathrm{~mm} ; 4 \mathrm{~mm} ; 2 \mathrm{~mm} ; 1 \mathrm{~mm} ; 0.5 \mathrm{~mm}$; $0.25 \mathrm{~mm} ; 0.125 \mathrm{~mm}$ and $0.063 \mathrm{~mm}$. The weight of the captured material on individual sieves was recorded in the table. Subsequently, the total percentages of the overflows were calculated over the individual sieves and we plotted the resulting grain curve for the fresh and modified old stabilizer (Fig. 6). Results of shares of fine-grained particles in samples of stabilizers using a laser granulometry method using a Mastersizer 2000 laser granulometer (Malvern, UK) are part of Fig. 7. By comparing the results of the measurements of fresh and old stabilizers, it can be stated that after crushing there are no significant changes with regard to

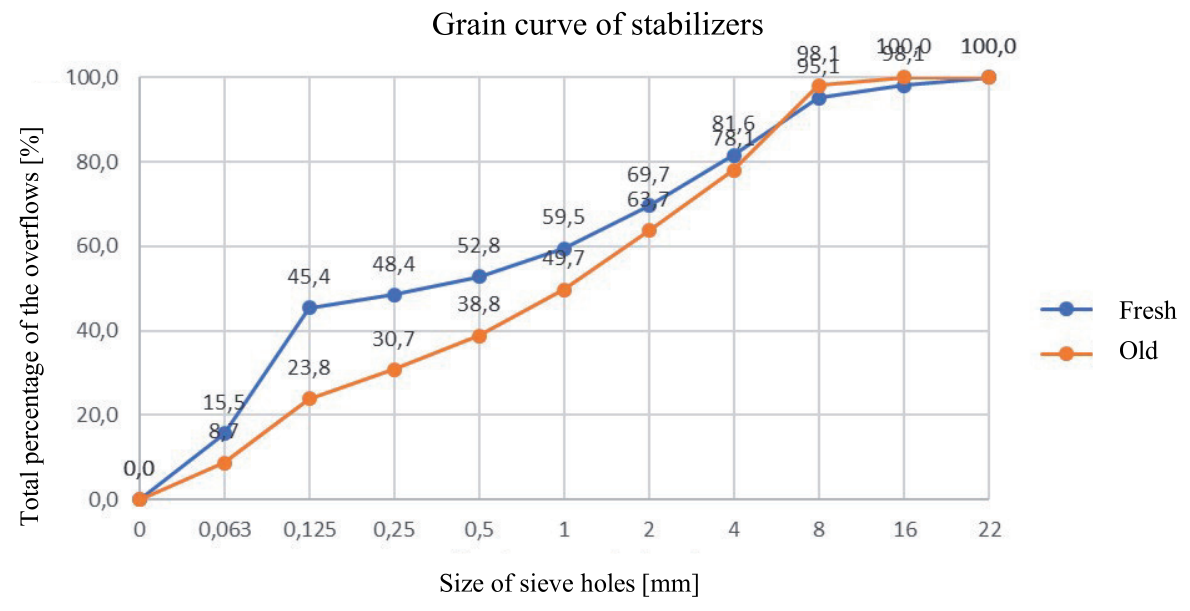

Fig. 6. Grain composition of test stabilizers. 


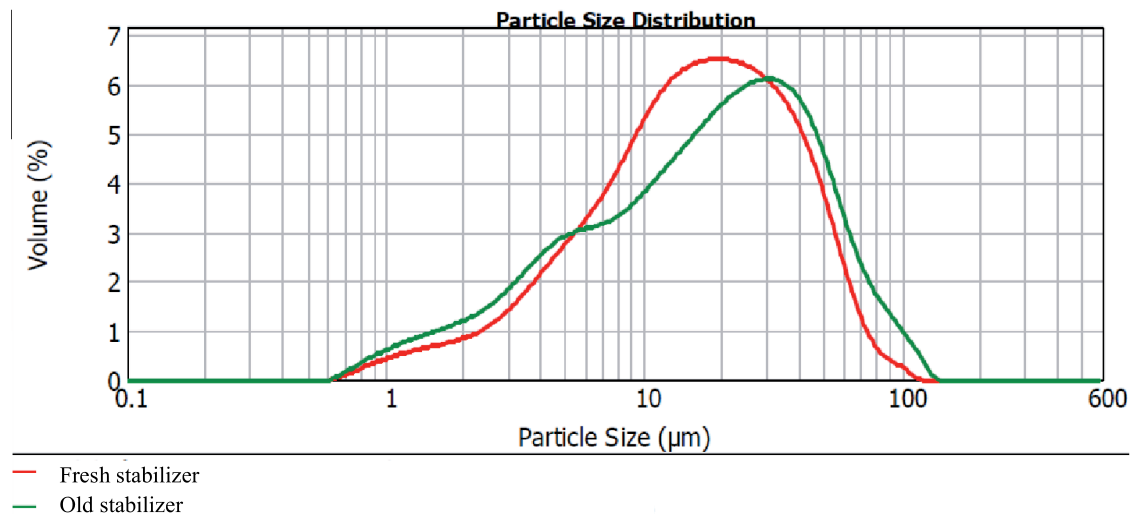

Fig. 7. Comparison of results of laser granulometry analyses.

the shares of the finest particles. There are only minor deviations in grain size.

The filtration coefficient for the test samples was determined from the measured data for eight test samples. The measurements for all test samples were realised three times and the result values are shown in Table 1.

The calculated values of the filtration coefficient indicate that the TB1 mixture $(100 \%$ content of the new stabilizer) reached the highest value and the TB3 mixture $(90 \%$ content of the new stabilizer, $10 \%$ content of the old stabilizer, homogeneous mixture) reached the lowest value of the filtration coefficient. However, it should be noted that the differences in the filtration coefficients between the mixtures are not significant and fall into one category between medium to low permeable substrates (equivalent of fine sand, loamy sand and sandy loam). From the testing of the hydraulic conductivity of the stabilizer samples, the following conclusions were drawn:

- The lowest permeability was shown by the sample with the finest crushed stabilizer.

- The highest permeability was observed in the sample with the thickest crushed stabilizer.

- The differences in the filtration coefficients between the individual test mixtures are not significant and fall into one category between medium to low permeable substrates (equivalent of fine sand, loamy sand and sandy loam).

- The greatest effect on the resulting permeability of the stabilizer layer will have the cracks created by the cyclic weathering load. Since the stabilizer is a fine-grained material, the risk of cracking is high when the moisture changes are high.

The results of the permeability testing of the stabilizer, respectively mixture formed by a combination of stabilizer and admixture which reflect the composition of testing fields directly on the tailing pond are contained in Table 2. Fig. 8 presents the permeability values measured under laboratory conditions (ex situ) and directly on the testing fields (in situ on February 19, 2018). It is clear from the above values that lower permeability values were largely achieved under laboratory conditions compared to field conditions. This phenomenon can be explained by slightly different techniques of preparing a mixture of stabilizers and their compaction in the field compared to laboratory conditions. The less favourable results from the field measurements were taken as guidelines. All of the reinforced stabilizer mixtures had a lower permeability than stabilizers without reinforcement. The lowest permeability was achieved by cementreinforced stabilizers. The old lime-reinforced stabilizer

Table 1. Results from testing hydraulic conductivity and calculating the filtration coefficients of test samples.

\begin{tabular}{|c|c|c|c|c|c|c|c|c|}
\hline \multirow{2}{*}{ Variable } & \multicolumn{9}{|c|}{ Value of test samples } \\
\cline { 2 - 10 } & TB1 & TB2 & TB3 & TB4 & TB5 & TB6 & TB7 & TB8 \\
\hline $\mathrm{k}[\mathrm{m} / \mathrm{s}]$ & $7,7 \mathrm{E}-06$ & $5,9 \mathrm{E}-06$ & $4,5 \mathrm{E}-06$ & $5,9 \mathrm{E}-06$ & $5,3 \mathrm{E}-06$ & $6,4 \mathrm{E}-06$ & $5,0 \mathrm{E}-06$ & $6,6 \mathrm{E}-06$ \\
\hline $\mathrm{a}\left[\mathrm{m}^{2}\right]$ & 0.00817 & 0.00817 & 0.00817 & 0.00817 & 0.00817 & 0.00817 & 0.00817 & 0.00817 \\
\hline $\mathrm{L}[\mathrm{m}]$ & 0.307 & 0.297 & 0.3 & 0.308 & 0.306 & 0.296 & 0.298 & 0.305 \\
\hline $\mathrm{A}\left[\mathrm{m}^{2}\right]$ & 0.00817 & 0.00817 & 0.00817 & 0.00817 & 0.00817 & 0.00817 & 0.00817 & 0.00817 \\
\hline $\mathrm{T}[\mathrm{s}]$ & 15030 & 14400 & 15510 & 15090 & 14340 & 15630 & 15630 & 18150 \\
\hline $\mathrm{h}_{0}[\mathrm{~m}]$ & 0.08 & 0.08 & 0.08 & 0.08 & 0.08 & 0.08 & 0.08 & 0.08 \\
\hline $\mathrm{h}_{\mathrm{t}}[\mathrm{m}]$ & 0.055 & 0.06 & 0.0635 & 0.06 & 0.0625 & 0.057 & 0.0615 & 0.054 \\
\hline
\end{tabular}


Table 2. Combination of stabilizer and admixture that reflects the composition of testing fields directly on the tailing pond.

\begin{tabular}{|c|c|c|c|c|c|}
\hline \multirow{2}{*}{ Item } & \multicolumn{5}{|c|}{ Combination of stabilizer and admixture } \\
\hline & The old stabilizer & The fresh stabilizer & Cement $32,5 \mathrm{~N}$ & Cement $42,5 \mathrm{~N}$ & Lime \\
\hline S & $100 \%$ & - & - & - & - \\
\hline $\mathrm{SC} 32,5-2 \%$ & $98 \%$ & - & $2 \%$ & - & - \\
\hline $\mathrm{SC} 32,5-5 \%$ & $95 \%$ & - & $5 \%$ & - & - \\
\hline $\mathrm{SC} 32,5-10 \%$ & $90 \%$ & - & $10 \%$ & - & - \\
\hline $\mathrm{SC} 42,5-2 \%$ & $98 \%$ & - & - & $2 \%$ & - \\
\hline $\mathrm{SC} 42,5-5 \%$ & $95 \%$ & - & - & $5 \%$ & - \\
\hline $\mathrm{SC} 42,5-10 \%$ & $90 \%$ & - & - & $10 \%$ & - \\
\hline SV-2\% & $98 \%$ & - & - & - & $2 \%$ \\
\hline SV-4\% & $96 \%$ & - & - & - & $4 \%$ \\
\hline SV-10\% & $90 \%$ & - & - & - & $10 \%$ \\
\hline $\mathrm{N}$ & - & $100 \%$ & - & - & - \\
\hline $\mathrm{N} 32,5-2 \%$ & - & $98 \%$ & $2 \%$ & - & - \\
\hline $\mathrm{N} 42,5-2 \%$ & - & $98 \%$ & - & $2 \%$ & - \\
\hline NV-2\% & - & $98 \%$ & - & - & $2 \%$ \\
\hline
\end{tabular}

exhibited a slightly higher permeability compared to the cement-reinforced stabilizer. In the case of cementreinforced stabilizers, there is no noticeable significant reduction in permeability with an increasing dose of cement. In the case of lime-reinforced stabilizer, mixtures with $4 \%$ and $10 \%$ were significantly less permeable than a $2 \%$ mixture. For all samples of the stabilizer, it is also possible after 90 and 120 days to suffer cracks in the body of the testing field (Fig. 9), incurred by combining of weather effects and a fine grain composition of the stabilizer. Cracks are more pronounced on the testing field with new stabilizer due to its finer-grained nature.
Puzzolans can be defined as materials containing amorphous reactive silica $\left(\mathrm{SiO}_{2}\right)$ and alumina $\left(\mathrm{Al}_{2} \mathrm{O}_{3}\right)$, which themselves have no or little binding ability. After mixing with calcium hydroxide $\left(\mathrm{Ca}(\mathrm{OH})_{2}\right)$ in the presence of water $\left(\mathrm{H}_{2} \mathrm{O}\right)$, they react at normal temperatures to form hydrated calcium compounds that are still under water to form solid connections between the filler grains. From a chemical point of view, they bring hydraulic components $\left(\mathrm{SiO}_{2}, \mathrm{Al}_{2} \mathrm{O}_{3}\right.$, $\mathrm{Fe}_{2} \mathrm{O}_{3}$ ) into the mixture, making them more resistant to acidic environments. Puzzolans activity is generally a slow chemical reaction, the rate of which depends on the concentration of $\mathrm{Ca}(\mathrm{OH})_{2}$ and $\mathrm{SiO}_{2}$ in the mixture.

$1,00 \mathrm{E}-06$

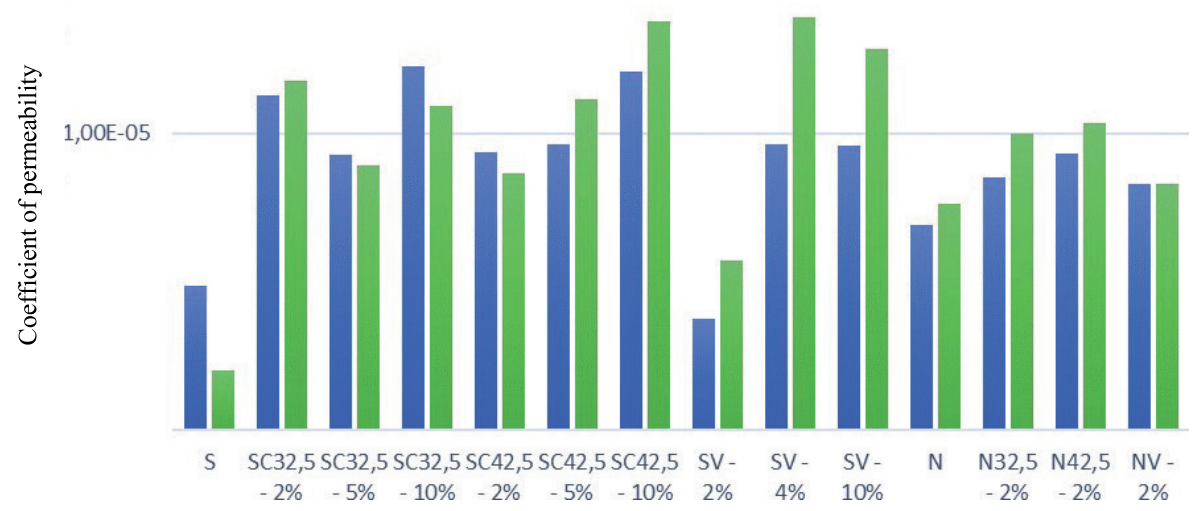

Fig. 8. Comparison of the coefficients of permeability after 120 days of reaction. 


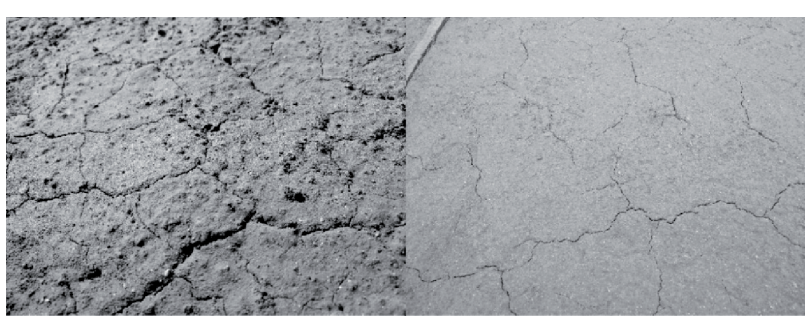

Fig. 9. Cracks in the body of the field.

The rate of puzzolanic reaction also affects the fineness of puzzolan, which means that with decreasing particles their reactivity increases and vice versa. For this reason, testing has been scheduled over a longer period of time, in this case up to 90 days. Puzzolan activity would be demonstrated by a gradual increase in strength over time as a consequence of the formation of new hydration products.

From a first view on the graph with the results of compressive strengths of the mixture of stabilizers (Fig. 10), there is a significant decrease in the compressive strength after 90 days compared to the strength after 28 days of hardening (average was reduced from $0.389 \mathrm{MPa}$ to $0.210 \mathrm{MPa}$ ). This phenomenon is beyond the normal behaviour of materials based on cement or hydraulic lime, where the opposite compressive strength increases with increasing time. This phenomenon can be explained by the presence of a higher concentration of sulphates in the stabilizer since it is made up of gypsum $\left(\mathrm{CaSO}_{4} \cdot 2 \mathrm{H}_{2} \mathrm{O}\right)$ with ash admixture (different ratio of $\mathrm{SiO}_{2}, \mathrm{Al}_{2} \mathrm{O}_{3}, \mathrm{Fe}_{2} \mathrm{O}_{3}$ and $\mathrm{CaO}$ ). In such an environment a certain sulphate concentration can occur due to reactions after the addition of material on a lime base (cement, lime), or minerals such as ettringite and taumasite. Ettringite formation is a complex phenomenon that has been described by several studies with regard to its long-term stability. Ettringite is a calcium aluminate sulphate formed in a high $\mathrm{pH}$ environment and in the presence of sulphates. Ettringite forms small fibrous crystals that damage the surrounding structure of the solid material due to expansion. At the same time, with the formation of ettringite, the formation of taumasite causes a decrease in the strengths of the silicate and calcareous materials. A decrease in the strength after 90 days of the samples of stabilizer would be possible is explained by the destructive effects of expanding ettringite and taumasite crystals. In this case, it is not possible to confirm puzzolans activity of the stabilizer in view of the prevailing adverse effects on the strength of stabilizer mixtures.

\section{Conclusions}

Several conclusions can be drawn from the above results of testing the stabilizers. The reinforcement of the stabilizers with cement and lime results in a reduction in their permeability, but the transmittance values of the test mixtures of stabilizers are not sufficient to form the sealing respectively water-permeable layer. Both the production of the testing fields and the laboratory tests of the stabilizer showed the formation of broad and long cracks that can substantially affect the permeability of the entire layer, regardless of the permeability of the material itself.

Cracking can be due to the fine-grained nature of the reinforced material, and its volume changes depending on the actual moisture conditions associated with the weathering effects. Cracking can also be related to the formation of additional sulphate compounds, e.g., ettringite, which increase their volume and act expansively on the layer of stabilizer, thereby breaking it. Due to some differences in the composition of the landfill body, it was necessary to perform a repeat test with samples of old stabilizers in order to generalize and unify the results of the experiments. Repeated measurement of stabilizer mixtures showed the same range of values as the first measurement.

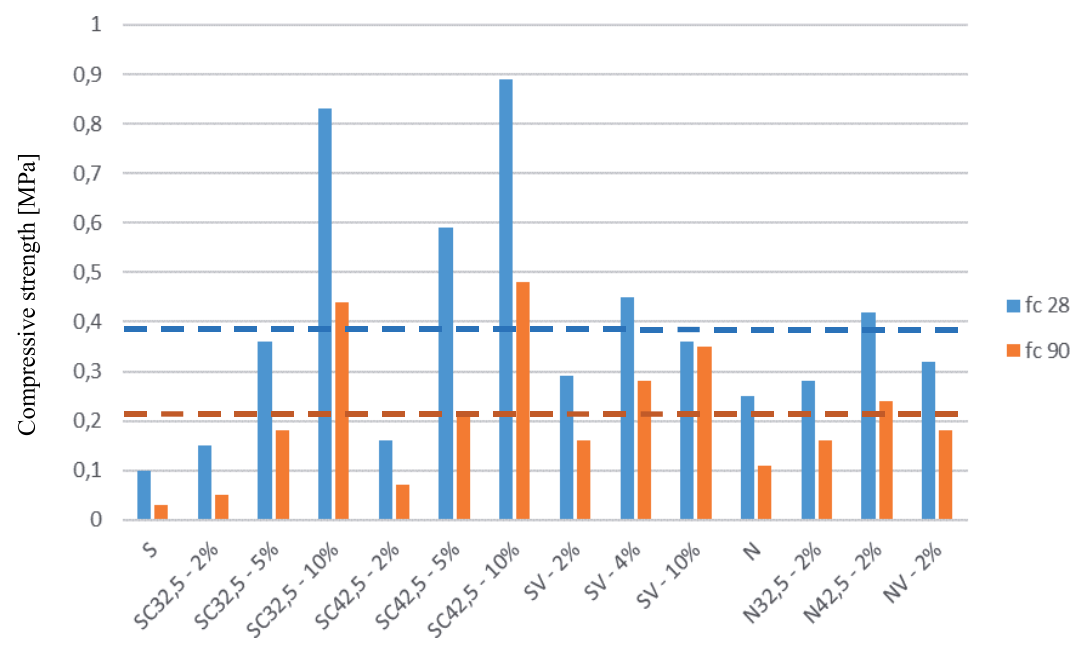

Fig. 10. Results of compression strength testing of mixtures of stabilizers after 28 and 90 days of hardening with average values. 


\section{Acknowledgements}

This article is written within the project of young scientists, young teachers and Ph.D. students number I-18-109-00

\section{Conflict of Interest}

The authors declare no conflict of interest.

\section{References}

1. DERMATAS D., MENG X. Utilization of fly ash for stabilization/solidification of heavy metal contaminated soils. Engineering Geology, 70 (3-4), 377, 2003.

2. AHMARUZZAMAN M. A review on the utilization of fly ash. Prog. Energ. Combust., 36, 327, 2010.

3. NILESH K. MAHALE, SACHIN D. PATIL, DHANANJAY B. SARODE, SANJAY B. ATTARDE. Effect of Fly Ash as an Admixture in Agriculture and the Study of Heavy Metal Accumulation in Wheat (Triticum aestivum), Mung Bean (Vigna radiata), and Urad Beans (Vigna mungo). Pol. J. Environ. Stud., 21, (6), 1713, 2012.

4. IYER R.S., IYER R.S., SCOTT J.A. Power station fly ash - a review of value-added utilization outside of the construction industry. Resources, Conservation and Recycling, 31, 217, 2001.

5. YAO Z.T., JI X.S., SARKER P.K., TANG J.H., GE L.Q., XIA M.S., XI Y.Q. A comprehensive review on the applications of coal fly ash. Earth-Science Reviews, 141, $105,2015$.

6. JAYANTHI P.N., SINGH D.N. Utilization of sustainable materials for soil stabilization: state-of-the-art. Advances in Civil Engineering Materials, 5, 46, 2016.

7. PHANIKUMAR B.R., SHARMA R.S. Volume change behavior of fly ash-stabilized clays. Journal of materials in Civil Engineering, 19, 67, 2007.

8. KAMON M., NONTANANANDH S. Combining industrial wastes with lime for soil stabilization. Journal of geotechnical engineering, 117, 1, 1991.

9. RAJAMMA R., BALL R.J., TARELHO L.A.C., ALLEN G.C., LABRINCHA J.A., FERREIRA V.M. Characterisation and use of biomass fly ash in cementbased materials. J. Hazard. Mater., 172, 1049, 2009.

10. ESTEVES T.C., RAJAMMA R., SOARES D., SILVA A.S., FERREIRA V.M., LABRINCHA J.A. Use of biomass fly ash for mitigation of alkali-silica reaction of cement mortars. Constr. Build. Mater., 26, 687, 2012.

11. WANG S., MILLER A., LLAMAZOS E., FONSECA F., BAXTER L. Biomass fly ash in concrete: Mixture proportioning and mechanical properties. Fuel, 87, 365, 2008.

12. KIZINIEVIC O., KIZINIEVIC V. Utilisation of wood ash from biomass for the production of ceramic products. Constr. Build. Mater., 127, 264, 2016.

13. RUIZ B., GIRÓN R.P., SUÁREZ-RUIZ I., FUENTE E. From fly ash of forest biomass combustion (FBC) to micro-mesoporous silica adsorbent materials. Process Saf. Environ., 105, 164, 2017.

14. JIMÉNEZ I., PÉREZ G., GUERRERO A., RUIZ B. Mineral phases synthesized by hydrothermal treatment from biomass ashes. Int. J. Miner. Proc., 158, 8, 2017.

15. XU R., LI F. Environmental impacts of coal ash from a power plant. In Environmental Science and Information Application Technology, ESIAT-2009, 1, 148, 2009.

16. TAKHELMAYUM G., SAVITHA A.L., KRISHNA G. Laboratory study on soil stabilization using fly ash mixtures. International Journal of Engineering Science and Innovative Technology - IJESIT, 2, 477, 2013.

17. CHANG A.C., LUND L.J., PAGE A.L., WARNEKE J.E. Physical Properties of Fly Ash-Amended Soils, Journal of Environmental Quality, 6, 267, 1977.

18. TKACZEWSKA E., MRÓZ R., ŁÓJ G. Coal-biomass fly ashes for cement production of CEM II/A-V 42.5R. Constr. Build. Mater., 28, 633, 2012.

19. KĘPYS W., PIOTROWSKI Z., POMYKAŁA R., GRZYWA A. Application of fly ash from biomass in suspension technologies. Inżynieria Mineralna-J. Pol. Min. Eng. Soc., 15, (2), 251, 2014.

20. KALEMBKIEWICZ J., CHMIELARZ U. Effects of Biomass Co-Combustion with Coal on Functional Speciation and Mobility of Heavy Metals in Industrial Ash, Pol. J. Environ. Stud. 22 (3), 741, 2013.

21. KIERCZAK J., CHUDY K. Mineralogical, Chemical, and Leaching Characteristics of Coal Combustion Bottom Ash from a Power Plant Located in Northern Poland, Pol. J. Environ. Stud. 23 (5), 1627, 2014.

22. CETIN S., PEHLIVAN E. The use of fly ash as a low cost, environmentally friendly alternative to activated carbon for the removal of heavy metals from aqueous solutions. Colloids and Surfaces A: Physicochemical and Engineering Aspects, 298, 83, 2007.

23. BOSÁK M., HAJDUOVÁ Z., MAJERNÍK M., ANDREJOVSKÝ P. Experimental-energy combustion of biomass combined with coal in thermal power plants. Pol. J. Environ. Stud., 24 (4), 1517, 2015. 